\title{
Associations between healthy eating patterns and indicators of metabolic risk in postmenopausal women
}

\author{
Ana P Tardivo1, Jorge Nahas-Neto', Eliana AP Nahas ${ }^{1 *}$, Nailza Maesta², Marcio AH Rodrigues ${ }^{1}$, Fabio L Orsatti ${ }^{1,2}$
}

\begin{abstract}
Background: Since human diets contain many components that may work synergistically to prevent or promote disease, assessing diet quality may be informative. The purpose of this study was to investigate the association between quality diet, by using Healthy Eating Index ( $\mathrm{HEl}$ ), and metabolic risk indicators in postmenopausal women.

Methods: This cross-sectional study included a total of 173 Brazilian women, aged 45-75 years, seeking healthcare at a public outpatient center. Food consumption assessed by 24 h-recall food inquiry was used to calculate HEl scores: >80 implied diet good, 80-51 diet "needed improvement", and $<51$ diet poor. Anthropometric data included: body mass index (BMI = weight/height ${ }^{2}$ ), waist-circumference (WC), body fat (\%BF) and lean mass (\%LM). Data on total cholesterol (TC), high density lipoprotein cholesterol (HDLC), low density lipoprotein cholesterol (LDLC), and triglycerides (TG) were also collected. Fisher's Exact test, and logistic regression method (to determine odds ratio, OR) were used in the statistical analysis.

Results: Overweight and obesity were observed in $75.7 \%$ of the participants. Excessive \%BF (> 35\%) was observed in $56.1 \%$, while \%LM was reduced $(<70 \%)$ in $78.1 \%$. WC was elevated $(\geq 88 \mathrm{~cm})$ in $72.3 \%$. Based on HEl values, diet quality was good in $3 \%(5 / 173)$, needed improvement in $48.5 \%$ (84/173), and was poor in $48.5 \%(84 / 173)$ of the cases. In this group, $75 \%$ of women had high intakes of lipids (> 35\%), predominantly saturated and monounsaturated fat. On average, plasma TC, LDLC, and TG levels were higher than recommended in 57.2\%, 79.2\% and $45.1 \%$ of the women, respectively, while HDLC was low in $50.8 \%$. There was association between HEI scores and the \%BF that it was higher among women with HEl score $<80(p=0.021)$. There were not observed significant risk associations between $\mathrm{HEl}$ and lipid profile.
\end{abstract}

Conclusion: Among the Brazilian postmenopausal women attending a public outpatient clinic, diet was considered to need improvement or to be of poor quality, attributed to high saturated fat ingestion, which probably caused a negative impact on metabolic risk indicators, namely body composition.

\section{Background}

Menopause is frequently associated with weight gain and a shift in body fat distribution. Once estrogen deficiency is established, a new pattern of fat distribution is observed - gluteo-femoral or gynecoid fat deposition decreases and abdominal or android fat accumulation increases $[1,2]$. Abdominal obesity is metabolically different from gynecoid obesity and contributes for the development of insulin-resistance, type 2 diabetes

\footnotetext{
* Correspondence: epetri@fmb.unesp.br

'Department of Gynecology and Obstetrics, Botucatu Medical School,

UNESP- Sao Paulo State University, Brazil

Full list of author information is available at the end of the article
}

mellitus, and dyslipidemia, components of metabolic syndrome, which are important risk markers of cardiovascular disease (CVD), the major cause of death among postmenopausal women [3]. Metabolic syndrome (MetS) is highly prevalent (39.6\%) among Brazilian postmenopausal women seeking gynecologic care, and abdominal obesity has been reported to be a strong MetS predictor [4]. Moreover, behavioral factors such as lifestyle, diet, sedentarism, smoking and alcohol use are associated with the onset and progress of atherosclerotic disease $[5,6]$.

Diet and eating habits have a pivotal role in maintaining human health. Unhealthy eating, obesity and 
nutritional deficiencies may lead to various diseases [7]. Modern dietary patterns, characterized by higher energy density, predispose to non-transmittable diseases such as type 2 diabetes mellitus, arterial hypertension and coronary heart disease that are directly associated with overweight and obesity $[8,9]$. Weight gain is related to the energy imbalance in which energy intake is greater than energy expenditure. This imbalance is influenced by diet quality, nutrient body metabolism and sedentarism associated with genetic susceptibility [10]. Thus, in order to treat and prevent diseases highly prevalent among postmenopausal women, the nutritional assessment of macronutrient (proteins, glycids and lipids) and micronutrient (calcium and iron) intake is necessary [11].

Since human diets contain many components that may work synergistically to prevent or promote disease, assessing diet quality may be more informative [12]. Indexes of dietary quality have been developed in recent years to address this shortcoming in nutrition research. The Healthy Eating Index (HEI) was developed to measure adherence to dietary guidelines (Food Guide Pyramid) and was shown to adequately measure overall diet quality [13]. Poor diet is a risk factor for many chronic diseases, including CVD. HEI is a validated instrument, that has been employed in several studies correlating the quality of diet and chronic diseases $[12,14,15]$. Relatively poor dietary quality, characterized by higher composite nutritional risk (higher dietary lipids and lower intakes of fiber and micronutrients), may predict the development of abdominal obesity independent of age, physical activity, or menopausal status [14].

Within this context, the primary purpose of this study was to investigate the association between dietary quality, by using a validated measure (HEI), and metabolic risk indicators in Brazilian postmenopausal women.

\section{Methods}

\section{Participant selection and study design}

This cross-sectional study was undertaken using a convenience sample consisting of 389 Brazilian postmenopausal women attending healthcare at a public outpatient center in Southeastern Brazil, between January and December 2009. All women aged $\geq 45$ years, without menstruation for at least 12 months, and in good health (self-rated) that agreed to participate were included in the study. A total of 216 women were excluded due to: (1) incomplete data; (2) refusal to undergo planned assessment procedures; (3) extremely low or high reported energy intakes $(<500$ or $>4,000$ $\mathrm{Kcal} / \mathrm{d}$ ); (4) ongoing dietary counseling with a doctor or dietitian; (5) use of drugs known to alter lipid metabolism; (6) non-controlled diabetes or thyroid diseases; and (7) special or vegetarian diet. All subjects were from low socioeconomic groups (income $\leq$ US\$ 500 per month). The study population was homogeneous and representative of the population attending in our service. Informed consent was obtained from all subjects and the Research Ethics Committee of Botucatu Medical School, Sao Paulo State University/UNESP, approved the study.

\section{Dietary intake measurements}

Initial evaluation consisted of a health questionnaire and general physical examination. Data collected included information on age, time since menopause, parity, hormone therapy (HT) use, physical activity and history of high-blood pressure, diabetes, cardiovascular disease, obesity, osteoporosis, and dyslipidemia. Women doing regular physical exercises for 30 minutes of moderateintensity aerobic activity at least five times a week or muscle-strengthening activities on two or more days a week were considered to be active [16].

A 24-hour dietary recall was obtained from every participant by a trained dietary interviewer (Tardivo, AP). The stepwise method, adapted from Thompson and Byers, was used [17]. The type and amount of foods consumed were recalled using recall aids such as abstract food models, special charts, measuring cups, and rulers to help in quantifying the amounts consumed. Special probes were used to help the recall of commonly forgotten items such as condiments, accompaniments, fast foods, etc. The nutritive value of the foods was also checked, especially with regard to the nutrients that are considered to be the greatest source of nutritive value for these foods. Thus, the 24-hour dietary recall data were controlled for errors that might have occurred in estimating nutrient intake. Based on these data, dietary habits as well as the dietary intake of proteins, carbohydrates, fat, and all known essential micronutrients were quantified using the Nutrition Software ("NutWin") [18].

Dietary intake data, as assessed by the 24-h recall, were used to calculate Healthy Eating Index (HEI) scores. HEI comprises 10 components (saturated fat, total fat, cholesterol, sodium, grain, fruit, dairy, meat, and vegetable intakes, plus a measure of dietary variety), each contributing 10 points to the maximum possible score of 100 [13]. Food serving amounts were computed from food consumption data using factors derived from the serving-size assumptions given in the Food Guide Pyramid [19]. Ten points were scored if saturated fat $\leq$ $10 \%$ of energy, total fat $\leq 30 \%$ of energy, cholesterol $\leq$ $300 \mathrm{mg}$, and sodium $\leq 2.4 \mathrm{mg}$. A zero score reflected $\geq$ $15 \%$ of energy for saturated fat, $\geq 45 \%$ of energy for total fat, cholesterol $\geq 450 \mathrm{mg}$, and sodium $\geq 4.8 \mathrm{mg}$; between these two cutoff points, scores were scaled proportionately. A similar process was used for food groups (grains, fruits, vegetables, dairy, and meat): consumption 
of the recommended number of servings for the individual's age and sex resulted in a score of 10 , with a score of 0 if no servings were consumed [20]. The maximum overall score for the 10 components combined is 100 . High component scores indicated intakes close to recommended ranges or amounts; low component scores indicated lower compliance. HEI scores $>80$ implied diet was "good", between 51 and 80 implied diet "needed improvement", and $<51$ implied diet was "poor" [21].

\section{Anthropometric measurements}

Anthropometric data included body mass index (BMI = weight $/$ height ${ }^{2}$ ), waist circumference (WC), waist/hip ratio (WHR), percentage of body fat (\%BF) and percentage of lean mass (\%LM). All anthropometric measures were taken under fasting conditions, and participants were wearing light-weight clothing and no shoes. The body mass index $\left(\mathrm{BMI}=\right.$ weight $/$ height $\left.^{2}\right)$ was used to assess weight variation. Height and weight were determined with a stadiometer (Seca ${ }^{\circ}$, Brazil) and a standard balance beam scale (Filizola ${ }^{\circ}$, Brasil), respectively. Weight was classified according to the system used by the World Health Organization (2002): $18.5-24.9 \mathrm{~kg} / \mathrm{m}^{2}$ = normal weight; $25-29.9 \mathrm{~kg} / \mathrm{m}^{2}=$ overweight; $\geq 30.0$ $\mathrm{kg} / \mathrm{m}^{2}=$ obesity.

Waist circumference (WC) was measured to the nearest $0.5 \mathrm{~cm}$ midway between the lowest rib margin and the top of iliac crest, and hip circumference at the largest posterior extension of the buttocks. Both were measured to the nearest $1 \mathrm{~cm}$ with an inelastic tape. Measurements were taken at the end of a normal respiration while subjects stood erect with arms hanging loosely at sides and feet were together. Abdominal fat was indirectly assessed by measuring waist circumference and was considered high when waist $>88 \mathrm{~cm}[22]$. The waist/hip ratio (WHR) was used to assess body fat distribution considering WHR $<0.80$ as a gynecoid pattern and WHR $\geq 0.80$ as an android pattern.

Body fat density was determined by the equation of Jackson et al. [23] based on tricipital, supra-iliac and thigh skin fold measurements that were taken three times with a Lange Skin fold Caliper (0.1-mm precision). Once density was calculated, the equation of Siri [24] was used to estimate body fat percentage. Adiposity was considered good when percentage $<25-30 \%$ of total body weight. Lean mass (LM) was obtained by subtracting absolute fat $(\mathrm{Kg})$ from total body weight and converting the result into percentage. LM was considered adequate when $>70 \%[25]$.

\section{Laboratory assessment}

Blood was collected from each subject after 12-hour fasting. A $12-\mathrm{ml}$ blood sample was drawn via venipuncture into vacuum tubes (Vacutainer ${ }^{\circ}$, England). Triglycerides (TG), total cholesterol (TC), high density lipoprotein cholesterol (HDLC), low density lipoprotein cholesterol (LDLC), and glucose levels were measured by the automatic biochemical analyzer Vitros 950 (Jonhson \& Jonhson, USA). Total cholesterol (TC), HDLC, triglycerides (TG) and glucose levels were quantified by the colorimetric test which provides a linear response over up to $800 \mathrm{mg} / \mathrm{dl}$ for triglycerides and $900 \mathrm{mg} / \mathrm{dl}$ for total cholesterol. LDLC was calculated using the formula of Friedewald et al. (1972), where total cholesterol is subtracted from the sum of HDLC and triglyceride divided by five. Normality rates were: $\mathrm{TC}<200 \mathrm{mg} / \mathrm{dl}$, HDLC $>50 \mathrm{mg} / \mathrm{dl}, \mathrm{LDLC}<100 \mathrm{mg} / \mathrm{dl}, \mathrm{TG}<150 \mathrm{mg} / \mathrm{dl}$ and glucose $<110 \mathrm{mg} / \mathrm{dL}$ [22].

\section{Statistical analysis}

A non-probability purposive sample was used. Sample size was determined based on the number of patients/ year attending the Climacterium Outpatient Service of Botucatu Medical School, Sao Paulo State University UNESP who met study inclusion criteria. Based on the data collected (quantitative variables), tables including patient characteristics and laboratory values expressed as median and interquartile range were generated. The classification variables were shown in numbers and percentage between parentheses. In the association of variables, patients were divided according to the values of HEI: $>80$, between $80-51$ and $<51$. For categorical variables, the comparison between groups was performed by Fisher's Exact Test.

Spearman correlation was used to assess correlations of dietary intake quality (HEI) with body composition parameters. Multivariate analysis, using a logistic regression model (odds ratio), was used to evaluate the influence of diet on lipid profile. In the model, the HEI value was considered as the independent variable while total cholesterol, HDLC, LDLC, and triglycerides were considered dependents variables. Age, time of menopause, and body mass index were used as adjusting variables in the models. Variable input to the regression model was considered at a significance level of $20 \%$ using a stepwise procedure. The statistical tests were bilateral, and the level of significance adopted was 5\%. The statistical analyses were processed by using software SAS, version 9.2 for Windows.

\section{Results}

Clinical characteristics and dietary intakes are shown in Table 1. Median age was 54.0 years and time since menopause was 6.0 years. The analysis of food intake indicators revealed that total daily calorie intake averaged 1,607.8 kcal, corresponding to $27 \mathrm{kcal} / \mathrm{kg}$ weight/ day. Protein caloric contribution averaged 15.4\%; 
Table 1 Clinical characteristics, dietary intakes, laboratory values and diet quality score for all subjects $(\mathrm{n}=\mathbf{1 7 3})$

\begin{tabular}{|c|c|c|}
\hline Parameters & Median $\left(25^{\text {th }} ; 75^{\text {th }}\right)^{*}$ & Range $^{* *}$ \\
\hline \multicolumn{3}{|l|}{ Clinical Characteristics } \\
\hline Age (years) & $54.0(49.0 ; 59.5)$ & $45-75$ \\
\hline Age at menopause (years) & $48.0(43.0 ; 51.0)$ & $33-55$ \\
\hline Time since menopause (years) & $6.0(2.0 ; 11.0)$ & $1-33$ \\
\hline \multicolumn{3}{|l|}{ Anthropometric measurement } \\
\hline $\mathrm{BMI}\left(\mathrm{kg} / \mathrm{m}^{2}\right)$ & $28.3(25.2 ; 31.5)$ & $19.1-42.3$ \\
\hline Waist circumference $(\mathrm{cm})$ & $94.5(87.1 ; 102.5)$ & $68-129.5$ \\
\hline WHR & $0.88(0.81 ; 1.0)$ & $0.50-1.21$ \\
\hline Body fat (\%) & $36.3(31.7 ; 39.8)$ & $20.5-51.5$ \\
\hline Lean Mass (\%) & $63.7(60.1 ; 68.3)$ & $48.5-84.7$ \\
\hline \multicolumn{3}{|l|}{ Dietary Intakes } \\
\hline Total energy intake (kcal/d) & $1607.8(1260.5 ; 1907.2)$ & 706.1-3617.8 \\
\hline Proteins (\%) & $15.4(12.6 ; 18.9)$ & $6.9-38.8$ \\
\hline Carbohydrate (\%) & $46.0(40.1 ; 54.3)$ & $24.1-66.5$ \\
\hline Lipid (\%) & $38.3(29.2 ; 44.3)$ & $18.6-68.4$ \\
\hline Saturated fat (\%) & $8.8(6.3 ; 11.7)$ & $3.2-18.2$ \\
\hline Monounsaturated fat (\%) & $10.4(8.2 ; 13.0)$ & 4.3-20.2 \\
\hline Polyunsaturated fat (\%) & $13.0(9.1 ; 16.8)$ & 4.6-29.7 \\
\hline HEl total score & $60.0(50.0 ; 70.0)$ & $30-90$ \\
\hline \multicolumn{3}{|l|}{ Biochemical Markers } \\
\hline Glucose (mg/dl) & $94.0(88.0 ; 99.5)$ & $75-216$ \\
\hline Total Cholesterol (mg/dL) & $210.0(180.0 ; 239.5)$ & 123-396 \\
\hline $\mathrm{HDLC}(\mathrm{mg} / \mathrm{dL})$ & $49.0(40.5 ; 58.0)$ & $28-92$ \\
\hline $\operatorname{LDLC}(\mathrm{mg} / \mathrm{dL})$ & $127.8(103.5 ; 156.5)$ & $53-299.8$ \\
\hline Triglycerides (mg/dL) & $151.0(89.5 ; 189.0)$ & $54-361$ \\
\hline
\end{tabular}

BMI, body mass index; WHR, waist/hip ratio; \%, percentage; HEI, Healthy Eating Index; high density lipoprotein cholesterol, HDLC; low density lipoprotein cholesterol, LDLC.

*Data are expressed as median with $25^{\text {th }}$ and $75^{\text {th }}$ percentiles in parentheses.

** Values minimum - maximum.

carbohydrates $(46.0 \%)$ and lipids $(38.3 \%)$ were the greatest sources of energy. Median saturated, polyunsaturated and monounsaturated fat intake was $8.8 \%, 10.4 \%$ and $13.0 \%$, respectively (Table 1). Cholesterol uptake was considered adequate $(<300 \mathrm{mg})$ in $88 \%$ of the cases. On the other hand, calcium uptake (>1200 mg) and iron uptake (>18 $\mathrm{mg}$ ) reached recommended levels in only $9 \%$ and $7 \%$ of the subjects, respectively. The median HEI score was 60.0, diet need improvement (Table 1).

Based on HEI values, diet quality was good in $3 \%$ (5/173), needed improvement in 48.5\% (84/173), and was poor in $48.5 \%(84 / 173)$ of the cases. The associations of descriptive characteristics according to the HEI scores were shown in Table 2 . Overweight and obesity were present in $75.7 \%(131 / 173)$ of the participants. Excessive body adiposity (> 35\%) was observed in $56.1 \%$ (97/173) of the subjects. Most women (72.3\%) showed greater fat concentration in the abdominal region (WC $>88 \mathrm{~cm}$ ) while lean mass was below normal $(<70 \%)$ in $78.1 \%$. Of the 173 women assessed $70(40.4 \%)$ were on hormone therapy (HT) (Table 2). None association was observed between HEI scores and clinical variables analyses ( $p$ > 0.05). Except for the percentage of body fat that it was higher among women with diet need improvement or poor $(\mathrm{p}=0.021)$ (Table 2$)$. There were no significant correlations between the values of HEI with BMI $(r=-0.52$, $\mathrm{p}=0.495), \mathrm{WC}(\mathrm{r}=-0.24, \mathrm{p}=0.753), \% \mathrm{BF}(\mathrm{r}=-0.139, \mathrm{p}$ $=0.069)$, and $\% \operatorname{LM}(\mathrm{r}=0,138, \mathrm{p}=0.71)$.

There were significant association between HEI values and dietary intakes in all macronutrients, as noted in Table 2. In the group with diet poor was observed that $75 \%$ of women had high intakes (> 35\%) of lipids, predominantly saturated and monounsaturated fat (Table 2). On average, plasma total cholesterol, LDLC, and TG levels were higher than recommended in $57.2 \%$ (99/ 173), $79.2 \%(137 / 173)$ and $45.1 \%(78 / 173)$ of the women, respectively, while HDLC was low in 50.8\% (88/ 173). None association was observed between HEI scores and biochemical markers analyses $(\mathrm{p}>0.05)$ (Table 2). In analyzing the impact of diet on lipid profile were not observed significant risk associations between HEI and total cholesterol (OR 0.966; CI 95\% 0.51-1.81), HDLC (OR 1.024; CI 95\% 0.55-1.91), LDLC (OR 1.194; CI 95\% 0.55-2.58), or triglycerides (OR 0.857; CI 95\% 0.46-1.59) (date not shown).

\section{Discussion}

The approach to menopause should be multidisciplinary and involve physicians, physical educators, physical therapists and nutritionists to increase survival and quality of life. Aging with quality of life requires appropriate nutritional management involving the balanced intake of macronutrients (carbohydrates, proteins, and lipids) and micronutrients in addition to an increased daily consumption of fruit, vegetables and whole grains (fiberrich) [26]. Poor diet quality has been considered a major determinant of obesity and is, therefore, an important variable to be investigated, especially in more vulnerable groups such as postmenopausal women [27]. In this study, Healthy Eating Index (HEI) assessment showed that in only $3 \%$ of the cases diet was of good quality, while in $48.5 \%$ it needed improvement and in $48.5 \%$ was of poor quality. Such poor quality was attributed to low whole-grain intake and high saturated fat ingestion, which probably caused a negative impact on metabolic risk indicators, namely body composition and lipoprotein profile.

Several studies have demonstrated the need for instruments capable of assessing dietary intake patterns as a whole in order to avoid the flaws associated with the evaluation of specific nutrients or foods $[21,28]$. Therefore, it is important to use a method with the ability to measure the quality of the food consumed such as HEI 
Table 2 Associations between diet quality scores (Healthy Eating Index, HEI) and clinical characteristics, dietary intakes, and biochemical markers of postmenopausal women $(n=173)$

\begin{tabular}{|c|c|c|c|c|c|}
\hline Characteristics & $\mathrm{N}$ & $\begin{array}{c}\text { Diet Good HEI }>80 \\
(n=5)\end{array}$ & $\begin{array}{l}\text { Diet Need Improvement HEI 80-51 } \\
\qquad(\mathrm{n}=84)\end{array}$ & $\begin{array}{l}\text { Diet poor HEI }<51 \\
(n=84)\end{array}$ & p value* \\
\hline Clinical Characteristics & & 0.779 & & & \\
\hline \multicolumn{6}{|l|}{ Age group (years) } \\
\hline$\leq 49$ & 44 & $0(0.0)$ & $23(52.3)$ & $21(47.7)$ & \\
\hline $50-59$ & 86 & $4(4.7)$ & $40(46.5)$ & $42(48.8)$ & \\
\hline$\geq 60$ & 43 & $1(2.4)$ & $21(48.8)$ & $21(48.8)$ & \\
\hline Age of menopause (years) & & 0.933 & & & \\
\hline$\leq 40$ & 29 & $0(0.0)$ & $15(51.7)$ & $14(48.3)$ & \\
\hline$\geq 41$ & 144 & $5(3.5)$ & $69(47.9)$ & 70 (48.6) & \\
\hline Menopause duration (years) & & 0.852 & & & \\
\hline$\leq 5$ & 85 & $3(3.5)$ & $42(49.4)$ & $40(47.1)$ & \\
\hline $6-10$ & 45 & $1(2.2)$ & $19(42.2)$ & $25(55.6)$ & \\
\hline$>10$ & 43 & $1(2.3)$ & $23(53.5)$ & $19(44.2)$ & \\
\hline Marital Status & & 0.619 & & & \\
\hline with partner & 124 & $4(3.2)$ & $57(46.0)$ & $63(50.8)$ & \\
\hline without partner & 49 & $1(2.0)$ & $27(55.1)$ & $21(42.9)$ & \\
\hline $\mathrm{BMI}\left(\mathrm{kg} / \mathrm{m}^{2}\right)$ & & 0.757 & & & \\
\hline$<25$ & 42 & $1(2.4)$ & $21(50.0)$ & $20(47.6)$ & \\
\hline $25-29,9$ & 68 & $3(4.4)$ & $35(51.5)$ & $30(44.1)$ & \\
\hline$\geq 30$ & 63 & $1(1.6)$ & $28(44.4)$ & $34(54.0)$ & \\
\hline Waist Circumference $(\mathrm{cm})$ & & 0.379 & & & \\
\hline$<88$ & 48 & $0(0.0)$ & $22(45.8)$ & $26(54.2)$ & \\
\hline$\geq 88$ & 125 & $5(4.0)$ & $62(49.6)$ & $58(46.4)$ & \\
\hline WHR & & 0.707 & & & \\
\hline$<80$ & 32 & $0(0.0)$ & $17(53.1)$ & $15(46.9)$ & \\
\hline$\geq 80$ & 141 & $5(3.6)$ & $67(47.5)$ & $69(48.9)$ & \\
\hline Body fat (\%) & & 0.021 & & & \\
\hline$<25$ & 12 & $1(8.3)$ & $3(25.0)$ & $8(66.7)$ & \\
\hline $25-35$ & 64 & $4(6.2)$ & $25(39.1)$ & $35(54.7)$ & \\
\hline$\geq 35$ & 97 & $0(0.0)$ & $56(57.7)$ & $41(42.3)$ & \\
\hline Lean Mass (\%) & & 0.279 & & & \\
\hline$<70$ & 136 & $4(2.9)$ & $70(51.5)$ & $62(45.6)$ & \\
\hline$\geq 70$ & 37 & $1(2.7)$ & $14(37.8)$ & $22(59.5)$ & \\
\hline Use of hormone therapy & & 0.316 & & & \\
\hline Yes & 70 & $3(4.3)$ & $40(57.2)$ & $27(38.5)$ & \\
\hline No & 103 & $2(1.9)$ & $44(42.7)$ & $57(55.4)$ & \\
\hline Physical exercise & & 0.406 & & & \\
\hline Yes & 35 & $0(0.0)$ & $20(57.1)$ & $15(42.9)$ & \\
\hline No & 138 & $5(3.6)$ & $64(46.4)$ & $69(50.0)$ & \\
\hline Smoking & & 0.264 & & & \\
\hline Yes & 45 & $0(0.0)$ & $26(57.8)$ & $19(42.2)$ & \\
\hline No & 128 & $5(3.9)$ & $58(45.3)$ & $65(50.8)$ & \\
\hline High-Blood Pressure $(\mathrm{mmHg})$ & & 0.801 & & & \\
\hline Yes & 70 & $1(1.4)$ & $35(50.0)$ & $34(48.6)$ & \\
\hline No & 103 & $4(3.9)$ & $49(47.6)$ & $50(48.5)$ & \\
\hline \multicolumn{6}{|l|}{ Dietary Intakes } \\
\hline Total energy intake (kcal/d) & & 0.005 & & & \\
\hline$<2000.0$ & 135 & $4(3.0)$ & $60(44.4)$ & $71(52.6)$ & \\
\hline$\geq 2000.0$ & 38 & $1(2.6)$ & $24(61.2)$ & $13(34.2)$ & \\
\hline Proteins (\%) & & 0.009 & & & \\
\hline$<10$ & 16 & $0(0.0)$ & $5(31.2)$ & $11(68.8)$ & \\
\hline
\end{tabular}


Table 2: Associations between diet quality scores (Healthy Eating Index, HEI) and clinical characteristics, dietary intakes, and biochemical markers of postmenopausal women $(n=173)$ (Continued)

\begin{tabular}{|c|c|c|c|c|}
\hline $10-35$ & 153 & $5(3.3)$ & $76(49.7)$ & $72(47.0)$ \\
\hline$>35$ & 4 & $0(0.0)$ & $3(75.0)$ & $1(25.0)$ \\
\hline Carbohydrate (\%) & & $<0.001$ & & \\
\hline$<45$ & 79 & $0(0.0)$ & $24(30.4)$ & $55(69.6)$ \\
\hline $45-65$ & 90 & $5(5.6)$ & $56(62.2)$ & $29(32.2)$ \\
\hline$>65$ & 4 & $0(0.0)$ & $4(100.0)$ & $0(0.0)$ \\
\hline Lipid (\%) & & $<0.001$ & & \\
\hline$<20$ & 3 & $0(0.0)$ & $3(100.0)$ & $0(0.0)$ \\
\hline $20-35$ & 74 & $5(6.8)$ & $57(77.0)$ & $12(16.2)$ \\
\hline$>35$ & 96 & $0(0.0)$ & $24(25.0)$ & $72(75.0)$ \\
\hline Saturated fat (\%) & & $<0.001$ & & \\
\hline$<7$ & 54 & $2(3.7)$ & $37(68.5)$ & $15(27.8)$ \\
\hline$\geq 7$ & 119 & $3(2.5)$ & $47(39.5)$ & $69(58.0)$ \\
\hline Monounsaturated fat (\%) & & $<0.001$ & & \\
\hline$<10$ & 78 & $4(5.1)$ & $53(67.9)$ & $21(27.0)$ \\
\hline$\geq 10$ & 95 & $1(1.0)$ & 31 (32.6) & $63(66.4)$ \\
\hline Polyunsaturated fat (\%) & & $<0,001$ & & \\
\hline$<10$ & 59 & $0(0.0)$ & $13(22.0)$ & $46(78.0)$ \\
\hline $10-15$ & 62 & $2(3.2)$ & $32(51.6)$ & $28(45.2)$ \\
\hline$>15$ & 52 & $3(5.7)$ & $39(75.0)$ & $10(19.3)$ \\
\hline \multicolumn{5}{|l|}{ Biochemical Markers } \\
\hline Glucose (mg/dL) & & 0.942 & & \\
\hline$\leq 100$ & 132 & $4(3.0)$ & $63(47.7)$ & $65(49.3)$ \\
\hline$>100$ & 41 & $1(2.4)$ & $21(51.2)$ & $19(46.4)$ \\
\hline Total Cholesterol (mg/dL) & & 0.804 & & \\
\hline$<200$ & 74 & $3(4.1)$ & $35(47.3)$ & $36(49.6)$ \\
\hline$\geq 200$ & 99 & $2(2.0)$ & $49(49.5)$ & $48(48.5)$ \\
\hline $\mathrm{HDLC}(\mathrm{mg} / \mathrm{dL})$ & & 0.884 & & \\
\hline$\geq 50$ & 85 & $3(3.5)$ & $40(47.1)$ & $42(49.4)$ \\
\hline$<50$ & 88 & $2(2.3)$ & $44(50.0)$ & $42(47.7)$ \\
\hline $\operatorname{LDLC}(\mathrm{mg} / \mathrm{dL})$ & & 0.877 & & \\
\hline$<100$ & 36 & $1(2.8)$ & $16(44.4)$ & $19(52.8)$ \\
\hline$\geq 100$ & 137 & $4(3.0)$ & $68(49.6)$ & $65(47.4)$ \\
\hline Triglycerides (mg/dL) & & 0.573 & & \\
\hline$<150$ & 95 & $4(4.2)$ & $46(48.4)$ & $45(47.4)$ \\
\hline$\geq 150$ & 78 & $1(1.3)$ & $38(48.7)$ & $39(50.0)$ \\
\hline
\end{tabular}

Data are expressed in numbers and in percentage between parentheses.

BMI, body mass index; WHR, waist hip ratio; high density lipoprotein cholesterol, HDLC; low density lipoprotein cholesterol, LDLC.

*Statistical difference between groups $p<0.05$ (Fisher's Exact test).

$[12,14,15]$. In our study, the mean HEI score was 56.6 (diet need improvement), lower than observations for the general US population of women $\geq 50$ years (mean HEI score 66.6) [21]. This finding is interesting because it is often assumed that volunteers for clinical trials are more health-conscious than the general population. The overall low diet quality was most likely due to the high intake dietary fat; our participants tended to score low on these variables. These results are in agreement with the study by Boynton et al [15] who found HEI scores (mean 63.1) slightly lower than those in the general US population. Specific data on dietary patterns and metabolic risks in Brazilian postmenopausal women are not available. In a study population of 3454 adults $(>20$ years) residing in Sao Paulo State, Brazil, the authors found that only $5 \%$ had a good diet, $74 \%$ had a diet that needed some degree of improvement and $21 \%$ had a poor diet [29]. However, almost $13 \%$ of the study sample consisted of subjects aged 60 years or more.

The postmenopausal participants were overweight with increased body fat percentage and waist circumference. Overweight and obesity were present in $39.3 \%$ and 
$36.4 \%$, of the participants, respectively. The results are consistent with data showing that the population is becoming overweight; approximately $66 \%$ of the female population in this age group is overweight or obese [30]. Identifying the type of body fat distribution is crucial because the accumulation of fat in the abdominal region is closely related with metabolic changes that can lead to the development of CVD and diabetes mellitus [31]. The Nurses' Health Study demonstrated that a high waist circumference is significantly associated with the increased rate of death by CVD observed in women with normal weight [3]. In our study was observed association between poor quality diet and the percentage of body fat. And the risk for detection of diet poor was significantly higher in women with elevated WC. Similarly to our results, Boynton et al. [15], evaluating 164 postmenopausal women, found that women with higherquality diets were more likely to have lower percent body fat.

Among study participants, the median of plasma total cholesterol, LDLC and triglycerides were above the desirable levels of the women, and HDLC was low. Besides tending to gain weight, postmenopausal women are susceptible to lipid metabolism changes due to estrogen deficiency that raises total cholesterol and lipoprotein levels producing a lipid profile highly favorable to atherogenesis $[32,33]$. A diet rich in refined carbohydrates, as observed in this present study, contributes for the development of atherosclerosis and increases cardiovascular risk, especially at 50-69 years of age [22]. Although the association of abnormal lipid profile with individual nutrients and food group has been well established, the relation between diet quality and lipids in women remains undocumented [34]. In this study analyzing the impact of diet on lipid profile were not observed significant risk associations between HEI and lipid profile. This can be attributed to the small number of women (only $3 \%$ ) with diet good. The vast majority of participants (97.1\%) had low-quality of diet, rich in lipids that could reflect the high rate of alteration in lipid profile. In agreement with our results, in the National Health and Nutrition Examination Survey (NHMES III), with 16,467 American adults (>17 years), lipid profile was not correlated with HEI scores [35].

Several studies investigated the influence of diet on cardiovascular risk by using predefined diet-quality scores [36]. These scores provide an overall estimate of dietary quality by quantifying and summing up a number of nutritional variables (foods and/or nutrients) that are considered to be important to health. In 2009, Hoekstra et al. [37] summarized outcomes of cohort studies on cardiovascular endpoints in women using a range predefined dietary-quality scores. Common components of the dietary-quality scores are intake of fruits and vegetables, cereals and quality of dietary fat. The protective effect of a healthy diet was consistent across all studies with reduction in cardiovascular ranging from $17 \%$ to $47 \%$ for the high quality versus low-quality diets. Thus, dietary counseling should be an integral part of the cardiovascular risk management in postmenopausal women. Manios et al. [38] studying changes in diet quality score, macro- and micronutrient intake following a nutrition education intervention in 75 postmenopausal women, found that the nutrition education program induced favorable changes for the intervention group in the intake of micronutrients primarily related to bone health and in total fat intake.

The energy intake considered ideal for body weight maintenance in women amounts to $1900 \mathrm{kcal} /$ day and $30 \mathrm{kcal} / \mathrm{kg}$ [20]. On average, these were the values obtained by the 24-h recall among study participants who reported the consumption of approximately 1800 $\mathrm{kcal}$ and $28 \mathrm{kcal} / \mathrm{kg}$. This information, however, is not consistent with the excessive body adiposity (>35\%) observed in $56.1 \%$ of these women. This underestimation of energy intake is likely to be due to the method used, which consists of remembering the amount and type of the food consumed, and the fact that obese individuals tend to underreport the actual amount taken. The assessment of nutrient intake involves comparing the typical daily intake with the requirements of an individual, despite the susceptibility of dietary assessment tools that are inherently prone to error [39]. Previous studies using the 24-h recall method demonstrated that current nutritional status is independent of the food ingested on the day preceding the interview as such dietary intake is too recent to directly influence obesity $[40,41]$.

The Acceptable Macronutrients Distribution Ranges (AMDR) proposed in 2005 by the National Academy of Sciences was $45 \%-65 \%$ for carbohydrates, $10 \%-35 \%$ for proteins, and $20 \%-35 \%$ for lipids. Regarding lipid intake, the ingestion of saturated, polyunsaturated and monounsaturated fat should be $<7 \%,<10 \%$ and $>$ superior $10-15 \%$ [20]. From the quantitative standpoint, the consumption of calories from carbohydrates and proteins observed in this study was within the recommended range. On the other hand, the ingestion of lipids was excessive and qualitatively inappropriate as saturated and polyunsaturated lipids were above recommended levels while monounsaturated lipids were at the lower limit of normality. Such inadequate lipid quality did not contribute for a greater cholesterol intake, which is explained by the type of food consumed.

The findings herein reported should be interpreted with caution as this study had some limitations. First, the sample size was relatively small due to the nature of the study design used (cross-sectional study based on a 
convenience sample) and the elevated rate of refusals to participate. The study population does not reflect the general population, so the results may not be extended to other population. Second, although 24-hour recalls are frequently used in dietary assessment, intake on a single day is a poor estimator of long-term usual intake; which may under or over estimated the HEI. Third, all subjects were from low socio-economic groups (income $\leq$ US\$ 500 per month) that have no access to nutritional education. Eating habits can be influenced by purchasing power, advertising and practicality in consumption. The rising trend toward highly energy-dense diets is stimulated by food industries that produce tasty foods containing high saturated fat and glucose levels and reduced fiber content at a relatively low cost [8]. This "modern" dietary pattern predisposes to obesity and cardiovascular diseases. Kant \& Graubard [42], using data from the National Health and Nutrition Examination Surveys (NHANES) I (1971-1975), II (1976-1980), III (1988-1994) and 1999-2002, examined the independent associations of poverty income ratio (PIR) and education with diet and biomarkers of diet and disease in 25-74year-olds $(n=36,600)$. A large PIR differential in the likelihood of reporting a fruit or all five-food groups intake, and an education differential in likelihood of obesity and carbohydrate intake, was noted. Unfavorable dietary and biomarker profiles in Americans with low income and education suggest continued need for improvement in the quality of diets of these high-risk groups.

\section{Conclusions}

Among the Brazilian postmenopausal women attending a public outpatient clinic, diet was considered to need improvement or to be of poor quality, attributed to high saturated fat ingestion, which probably caused a negative impact on metabolic risk indicators, namely body composition.

\section{Author details}

${ }^{1}$ Department of Gynecology and Obstetrics, Botucatu Medical School, UNESP- Sao Paulo State University, Brazil. ${ }^{2}$ Nutrition and Exercise Metabolism Center of Department of Public Health, Botucatu Medical School, UNESPSao Paulo State University, Brazil.

\section{Authors' contributions}

JNN, EAPN, NM contributed to the conceptualization and design, interpretation and writing of the article. APT developed the research protocol and conducted the data collection. MAHR and FLO were responsible for data analyses. All authors critically reviewed the manuscript and approved the final version submitted for publication.

\section{Competing interests}

The authors declare that they have no competing interests.

Received: 25 May 2010 Accepted: 8 December 2010 Published: 8 December 2010
References

1. Toth MJ, Tchernof A, Sites CK, Poehlman ET: Effect of menopausal status on body composition and fat distribution. Int J Obes Relat Metab Disord 2000, 24:226-31.

2. Sowers MF, Zheng $H$, Tomey $K$, Karvonen-Gutierrez C, Jannausch M, Li X, Yosef $M$, Symons J: Changes in Body Composition in Women over Six Years at Midlife: Ovarian and Chronological Aging. J Clin Endocrinol Me tab 2007, 92:895-901.

3. Zhang C, Rexrode KM, van Dam RM, Li TY, Hu FB: Abdominal Obesity and the Risk of All-Cause, Cardiovascular, and Cancer Mortality. Sixteen Years of Follow-Up in US Women. Circulation 2008, 117:1658-67.

4. Nahas EAP, Padoani NP, Nahas-Neto J, Orsatti FL, Tardivo AP, Dias R: Metabolic syndrome and its associated risk factors in Brazilian postmenopausal women. Climacteric 2009, 12:431-8.

5. Kannel WB, D'Agostino RB, Sullivan L, Wilson PWF: Concept and usefulness of cardiovascular risk profiles. Am Heart J 2004, 148:16-26.

6. De Caterina R, Zampolli A, Del Turco S, Madonna R, Massaro M: Nutritional mechanisms that influence cardiovascular disease. Am J Clin Nutr 2006, 83:421S-6S.

7. Pines A: Lifestyle and diet in postmenopausal women. Climacteric 2009, 12(suppl1):62-5.

8. Drewnowski A: Nutrition transition and global dietary trends. Nutrition 2000, 16:486-7.

9. Ledikwe JH, Blanck HM, Kettel Khan L, Serdula MK, Seymour JD, Tohill BC, Rolls BJ: Dietary energy density is associated worth energy intake and weight status in US adults. Am J Clin Nutr 2006, 83:1362-8.

10. Martinez JA: Body weight regulation: causes of obesity. Proc Nutr Soc 2000, 59:337-45.

11. Institute of Medicine: Dietary Reference Intakes: Applications in Dietary Assessment. Washington: National Academy Press; 2000.

12. Boynton A, Neuhouser ML, Wener MH, Wood B, Sorensen B, Chen-Levy Z, Kirk EA, Yasui Y, La Croix K, McTiernan A, Ulrich CM: Associations between healthy eating patterns and immune function or inflammation in overweight or obese postmenopausal women. Am J Clin Nutr 2007, 86:1445-55.

13. Kennedy ET, Ohls J, Carlson S, Fleming K: The Healthy Eating Index: Design and applications. J Am Diet Assoc 1995, 95:1103-8.

14. Kant AK, Graubard Bl: A comparison of three dietary pattern indexes for predicting biomarkers of diet and disease. J Am Coll Nutr 2005, 24:294-303.

15. Boynton A, Neuhouser ML, Sorensen B, McTiernan A, Ulrich C: Predictors of Diet Quality among Overweight and Obese Postmenopausal Women. J Am Diet Assoc 2008, 108:125-30.

16. Centers for Disease Control and Prevention. [http://www.cdc.gov/ nccdphp/dnpa/physical/pdf/PA_Fact_Sheet_OlderAdults.pdf].

17. Thompson FE, Byers T: Dietary assessment resource manual. J Nutr 1994 124(suppl 11S):2245-2317.

18. Anção $M S$, Cuppari $L$, Draibe $A S$, Sigulem D: Programa de Apoio à nutrição - NutWin, versão 1.5 [CD ROM]. São Paulo: Departamento de Informática em Saúde - SPDM - UNIFESP/EPM; 2002.

19. U.S. Department of Agriculture: The Food Guide Pyramid Washington DC: US Government Printing Office; 1992.

20. National Academy of Sciences: Dietary Reference Intakes for Energy, Carbohydrate, Fiber, Fat, Fatty acids, Cholesterol, Protein, and Aminoacids (macronutrients). Washington: National Academy Press; 2005.

21. Basiotis P, Carlson A, Gerroir S, Juan W, Lino M: The Healthy Eating Index: 1999-2000. Washington, DC: US Department of Agriculture, Center for Nutrition Policy and Promotion; 2002, Publication No. CNPP-12.

22. NCEP Expert Panel on the detection and treatment of high blood pressure in adults: Executive summary of the Third Report of the National Cholesterol Education Program (NCEP). Adult Treatment Panel III (ATP III). JAMA 2001, 285:2444-9.

23. Jackson $A S$, Pollock $M L$, Ward $A$ : Generalized equations for predicting body density of women. Med Scie Sports Exerc 1980, 12:175-82.

24. Siri WE: Body composition from fluid spaces and density: Analysis of methods. In Techniques for measuring body composition 1961. Edited by: Brozek J, Henschel A. Washington: National Academy of Sciences; 1981:223-44

25. Bray G: An approach to the classification and evaluation of obesity.Edited by: Bjorntorp P, Brodoff BN. Obesity. Philadelphia: J. B. Lippincott; 1992:294-308. 
26. Haveman-Nies A, Tucker KL, de Groot LC, Wilson PW, van Staveren WA: Evaluation of dietary quality in relationship to nutritional and lifestyle factors in elderly people of the US Framinghan Heart Study and the European SENECA study. Eur J Clin Nutr 2001, 55:870-80.

27. Millen BE, Pencina MJ, Kimokoti RW, Meigs JB, Ordovas JM, D'Agostino RB: Nutritional risk and the metabolic syndrome in women: opportunities for preventive intervention from the Framingham Nutrition Study. Am J Clin Nutr 2006, 84:434-41.

28. Weinstein SJ, Vogt TM, Gerrior AS: Healthy Eating Index scores are associated with blood nutrient concentrations in the third National Health and Nutrition Examination Survey. J Am Diet Assoc 2004, 104:576-84

29. Fisberg R, Morimoto JM, Slater B, Barros MBA, Carandina L, Goldbaum M, Oliveira Latorre MR, Cesar CR: Dietary quality and associated factors among adults living in the State of Sao Paulo, Brazil. J Am Diet Assoc 2006, 106:2067-72

30. Ogden $C L$, Carroll MD, Cutin LR, McDowell MA, Tabak CJ, Flegal KM: Prevalence of overweight and obesity in the United States, 1999-2004. JAMA 2006, 295:1549-55.

31. Grundy SM, Hansen B, Smith SC Jr, Cleeman Jl, Kahn RA, American Heart Association; National Heart, Lung, and Blood Institute; American Diabetes Association: Clinical management of metabolic syndrome: report of the National Heart, Lung and Blood Institute/American Heart Association Conference on Scientific Issues Related to Definition. Circulation 2004, 109:551-6.

32. Berg G, Mesch V, Boero L, Sayegh F, Prada M, Royer M, Muzzio ML, Schreier L, Siseles N, Benencia H: Lipid and lipoprotein profile in menopausal transition. Effects of hormones, age and fat distribution. Horm Metab Res 2004, 36:215-20.

33. Mosca L, Banka CL, Benjamin EJ, Berra K, Bushnell C, Dolor RJ, Ganiats TG, Gomes AS, Gornik HL, Gracia C, Gulati M, Haan CK, Judelson DR, Keenan N, Kelepouris E, Michos ED, Newby LK, Oparil S, Ouyang P, Oz MC, Petitti D, Pinn WW, Redberg RF, Scott R, Sherif K, Smith SC Jr, Sopko G, Steinhorn RH, Stone NJ, Taubert KA, et al: Evidence-Based Guidelines for Cardiovascular Disease Prevention in Women: 2007 Update. Circulation 2007, 115:1481-1501.

34. Shah BS, Freeland-Graves JH, Cahil JM, Lu H, Graves GR: Diet quality as measured by the health eating index and the association with lipid profile in low income women in early postpartum. J Am Diet Assoc 2010, 110:274-9.

35. Weintein SJ, Vogt TM, Genior SA: Health eating index scores are associated with blood nutrients concentration in the Third National Health and Nutrition Examination Survey. J Am Diet Assoc 2004, 104:576-84.

36. Iqbal R, Anand S, Ounpuu S, Islam S, Zhang X, Rangarajan S, Chifamba J, AlHinai A, Keltai M, Yusuf S, on behalf of the INTERHEART Study Investigators: Dietary Patterns and the Risk of Acute Myocardial Infarction in 52 Countries. Circulation 2008, 118:1929-37.

37. Hoekstra T, Beulens J, van der Schouw Y: Cardiovascular disease prevention in women: impact of dietary interventions. Maturitas 2009, 63:20-7.

38. Manios Y, Moschonis G, Katsaroli I, Grammatikaki E, Tanagra S: Changes in diet quality score, macro-and micronutrients intake following a nutrition education intervention in postmenopausal women. J Hum Nutr Diet 2007, 20:126-31.

39. Horner NK, Patterson RE, Neuhouser ML, Lampe JW, Beresford SA, Prentice RL: Participant characteristics associated with errors in selfreported energy intake from the Women's Health Initiative food frequency questionnaire. Am J Clin Nutr 2002, 76:766-773.

40. Wing R, Matthews KA, Kuller LH, Meilahn EL, Plantinga PL: Weight gain at the time of menopause. Arch Intern Med 1991, 151:97-103.
41. Albu J, Shur M, Curi M, Murphy L, Heymsfield SB, Py-Sunyer FX: Resting metabolic rate in obese, premenopausal black women. Am J Clin Nutr 1997, 66:531-8.

42. Kant AK, Graubard BI: Secular trends in the association of socio-economic position with self-reported dietary attributes and biomarkers in the US population: National Health and Nutrition Examination Survey (NHANES) 1971-1975 to NHANES 1999-2002. Public Health Nutr 2007, 10:158-67.

doi:10.1186/1475-2891-9-64

Cite this article as: Tardivo et al:: Associations between healthy eating patterns and indicators of metabolic risk in postmenopausal women. Nutrition Journal 2010 9:64.

\section{Submit your next manuscript to BioMed Central and take full advantage of:}

- Convenient online submission

- Thorough peer review

- No space constraints or color figure charges

- Immediate publication on acceptance

- Inclusion in PubMed, CAS, Scopus and Google Scholar

- Research which is freely available for redistribution

Submit your manuscript at www.biomedcentral.com/submit
Biomed Central 